\title{
Nuevas agendas urbanas: alineación con los Objetivos de Desarrollo Sostenible e integración de las ONG y Sociedad Civil. Estrategia y objetivos de ICOMOS
}

José A. Alonso Campanero | ICOMOS, representante del Comité Nacional de España en la Comisión Estratégica de la Agenda 2030 y Cambio Climático

URL de la contribución <http://www.iaph.es/revistaph/index.php/revistaph/article/view/4398>

En 2030, 6 de cada 10 personas vivirán en zonas urbanas. Hasta ahora, la concentración en urbes se ha visto como una consecuencia positiva del crecimiento y desarrollo, siendo el $85 \%$ de PIB mundial generado en las ciudades.

A su vez, las ciudades consumen el $75 \%$ de los recursos naturales y son responsables del $80 \%$ de las emisiones de efecto invernadero. Por ello, unido a maximización de oportunidades de desarrollo económico y social, será necesario gestionar los desafíos provocados por la urbanización, tales como el crecimiento de las desigualdades, el impacto medioambiental, el deterioro de las infraestructuras o la seguridad.

Todos estos retos y oportunidades han sido recogidos a nivel global en diferentes documentos desde la adopción en 2015 de los Objetivos de Desarrollo Sostenible, diseñando estrategias muy focalizadas.

Así, el impacto del crecimiento urbano fue abordado por la Nueva Agenda Urbana, aprobada en Quito en 2016, a la que han seguido una decidida apuesta de otras organizaciones internacionales, como la Organización Mundial del Turismo, UNESCO y otras europeas, por la implementación de estrategias encaminadas a poner en valor y proteger el patrimonio cultural.

En este contexto, se ha hecho necesario que instituciones y gobiernos desarrollen sus políticas desde una perspectiva holística y apliquen nuevas metodologías de gestión e incorporen e involucren a los diferentes grupos de interés en la definición e implementación de sus estrategias.
A nivel global, las agendas, han sido fruto de un amplio proceso de consulta a distintos niveles: gubernamental, empresarial, academia, ONGs y sociedad civil. Ahora bien, al intentar desarrollar a nivel local dichas agendas, será necesario seguir trabajando en la incorporación de los distintos stakeholders en cada una de las fases: desde diseño hasta la implantación, seguimiento e incorporación de acciones correctoras.

En el ámbito nacional, el interés político y social creciente en estos aspectos se ha concretado entre otros con la creación de un Alto Comisionado para la Agenda 2030, el Comisionado para el Reto Demográfico, el desarrollo de la Agenda Urbana Española y otras actualmente en desarrollo a nivel local.El amplio proceso de consulta y el enfoque cooperativo que se ha incorporado en la esfera internacional ha permitido también que, a nivel local, el rol de las ONGs y de la sociedad civil haya ganado poder de influencia como actores definitivos tanto en la definición de políticas (top-down approach) como en la implementación y la detección de necesidades (bottom-up approach).

Conocedores de las oportunidades y desafíos a los que nos enfrentamos y de la necesidad de integración transversal de la conservación del patrimonio cultural en las estrategias mencionadas, las principales líneas de trabajo de ICOMOS se centran en tres líneas maestras:

\section{Alineación}

Tiene como objetivo impulsar el desarrollo de acciones en línea con la Agenda 2030. Teniendo el Objetivo 11 "Ciudades y Comunidades Sostenibles", y en concreto, la meta 11.4 "Proteger y salvaguardar el Patrimonio 
a debate El papel del patrimonio en las nuevas políticas para la cultura, la ciudad y el territorio: las agendas urbanas como marco de oportunidad

| coordinan Blanca del Espino Hidalgo, Rafael Merinero Rodríguez

Cultural y Natural", se trabaja en comités y grupos de trabajo específicos y multidisciplinares que aborden retos relacionados con el consumo y producción responsable (ODS12. Meta 12b); turismo sostenible (ODS 14. Meta 14.7) Promoción de la cultura y productos locales (ODS 8 y 12. Meta 8.9), Desastres (ODS 11, 13), Cultura y naturaleza (ODS 15 y 16), Turismo Cultural (ODS 8, 12, 14, 15) y Cambio Climático (ODS 13).

De igual modo, se facilita el establecimiento y desarrollo de alianzas para el trabajo en proyectos conjuntos, asesoramiento y estudios, identificando y contribuyendo al desarrollo de programas relacionados con la conservación del patrimonio cultural en otras agendas de Naciones Unidas como cambio climático (París), reducción de riesgos (Sendai) o financiación para el desarrollo (Adis Abebba) entre otros.

\section{Implementación, análisis y estudio}

Tiene como objetivo la construcción de visibilidad y conciencia a nivel nacional y local, preparando documentos técnicos y de divulgación, identificando a los actores del sector público o grupos de interés, y ofreciendo soporte técnico (preferentemente a administraciones locales) en turismo cultural, patrimonio mundial o listas tentativas.

Finalmente, la creación de un portfolio de casos de estudio en los cuales se identifiquen buenas prácticas de integración de conservación y desarrollo sostenible en patrimonio cultural y el desarrollo de una estrategia de red con otras organizaciones con intereses y misiones complementarias para sumar fuerzas, conocimiento e influencia.

\section{Monitorización}

Tiene como objetivo la medición del impacto de las acciones llevadas a cabo mediante indicadores, siguiendo las líneas maestras de UNESCO "Culture for Development Indicators" y creando metodologías que puedan registrar otros datos tales relativos a actividades educativas, participación social, empleo, sostenibilidad o economía.
Como conclusión, desde ICOMOS vemos que la inclusión de la sociedad civil tanto en la elaboración de la Agenda 2030, como en la Nueva Agenda Urbana tendrá su reflejo a nivel local en la elaboración de políticas públicas y el papel del tercer sector disfrutará de una oportunidad definitiva de influir a nivel local en lo que ya trabajó a nivel global. 